\title{
Application of a Novel Semiconductor Catalyst, CT, in Degradation of Aromatic Pollutants in Wastewater: Phenol and Catechol
}

\author{
Xiao Chen, ${ }^{1,2}$ Yanling Zhang, ${ }^{3}$ Xuefei Zhou, ${ }^{2}$ Shoji Ichimura, ${ }^{4}$ Guoxiu Tong, \\ Qiming Zhou, ${ }^{1,3}$ Xi Chen, ${ }^{5}$ Wenzhao Wang, ${ }^{3}$ and Yan Liang ${ }^{1,3,5,6}$ \\ ${ }^{1}$ Department of Biology, Hong Kong Baptist University, Kowloon, Hong Kong \\ ${ }^{2}$ College of Environmental Science \& Engineering, Tongji University, Shanghai, China \\ ${ }^{3}$ Shenzhen Institutes of Advanced Technology, Chinese Academy of Sciences, Shenzhen 518055, China \\ ${ }^{4}$ FIRAC International Co., Ltd., 455-1 Fukude, Fukude-Cho Iwata-Gun, Shizuoka 437-1203, Japan \\ ${ }^{5}$ Xinjiang Institute of Ecology and Geography, Chinese Academy of Sciences, P.O. Box 9825, Beijing 100029, China \\ ${ }^{6}$ Laboratory for Food Safety and Environmental Technology, Institute of Biomedicine and Biotechnology, \\ Shenzhen Institutes of Advanced Technology, Chinese Academy of Sciences, Shenzhen 518055, China
}

Correspondence should be addressed to Xuefei Zhou; zhouxuefei@tongji.edu.cn and Yan Liang; yan.liang@siat.ac.cn

Received 15 November 2013; Revised 10 February 2014; Accepted 10 February 2014; Published 14 April 2014

Academic Editor: Fan Dong

Copyright (c) 2014 Xiao Chen et al. This is an open access article distributed under the Creative Commons Attribution License, which permits unrestricted use, distribution, and reproduction in any medium, provided the original work is properly cited.

\begin{abstract}
Water-soluble phenol and phenolic compounds were generally removed via advanced oxidation processes. A novel semiconductor catalyst, CT, was the first-time employed in the present study to degrade phenol and catechol. The phenolic compounds (initial concentration of $88 \mathrm{mg} \mathrm{L}^{-1}$ ) were completely mineralized by the CT catalytic nanoparticles (1\%) within 15 days, under acidic condition and with the presence of mild UV radiation ( $15 \mathrm{w}$, the emitted wavelength is $254 \mathrm{~nm}$ and the light intensity $<26 \mu \mathrm{w} / \mathrm{cm}^{2}$ ). Under the same reaction condition, $1 \% \mathrm{TiO}_{2}$ (mixture of rutile and anatase, nanopowder, $<100 \mathrm{~nm}$ ) and $\mathrm{H}_{2} \mathrm{O}_{2}$ had lower removal efficiency (phenol: $<42 \%$; catechol: $<60 \%$ ), whereas the control (without addition of catalysts $/ \mathrm{H}_{2} \mathrm{O}_{2}$ ) only showed $<12 \%$ removal. The processes of phenol/catechol removal by CT followed pseudo-zero-order kinetics. The aromatic structures absorbed the UV energy and passed to an excited state, which the CT worked on. The pollutants were adsorbed on the CT's surface and oxidized via charge-transfer and hydroxyl radical generation by CT. Given low initial concentrations, a circumstance encountered in wastewater polishing, the current set-up should be an efficient and less energy- and chemical-consumptive treatment method.
\end{abstract}

\section{Introduction}

Phenol and phenolic substances, such as catechol and hydroquinone, are widely used as raw materials in petrochemical, chemical, and pharmaceutical industries [1]. They also occur in various common phenolated industrial effluents, with concentrations ranging between 35 and $8000 \mathrm{mg} \mathrm{L}^{-1}$ [2]. These highly water-soluble and stable compounds are toxic, carcinogenic, mutagenic, and teratogenic [3] and potentially may lead to adverse effects in human and aquatic organisms [4]. Therefore, their concentrations in the industrial effluents are usually regulated. For example, in China, phenol at concentrations above $0.3 \mathrm{~m} \mathrm{~L} \mathrm{~L}^{-1}$, respectively, is not allowed to be discharged to the natural water bodies, according to the Integrated Wastewater Discharge Standard [5].

Treatment processes for phenolic wastewater include physical, biological, and chemical methods. High concentration phenolic wastewaters refer to those with phenol more than $1000 \mathrm{mg} \mathrm{L}^{-1}$, which are recycled via methods such as adsorption or solvent extraction [6-8]. Intermediate concentration phenolic wastewaters are those with phenol levels between 5 and $500 \mathrm{mg} \mathrm{L}^{-1}$, which are treated by biological methods [9] or chemical oxidation [10]. Generally speaking, it is practically impossible to remove phenol and phenolic substances simply by using conventional biologic treatment [11]. Advanced oxidation processes (AOPs) have been widely 
used for the treatments over the last few decades. Particularly, AOPs combining oxidants (e.g., ozone and $\mathrm{H}_{2} \mathrm{O}_{2}$ ), UV radiation, catalysts (e.g., $\mathrm{TiO}_{2}$ and $\mathrm{V}_{2} \mathrm{O}_{5}$ ), and ultrasound have received most of the attention [12]. For example, Gurol and Vatistas [13] treated mixtures of phenol, p-cresol, 2, 3-xylenol, and catechol by ozone, UV light, and a combination of ozone and UV light (photolytic ozonation). They observed that the photolytic ozonation removed more than $95 \%$ of the total organic carbon (much higher than the $<30 \%$ of the removal by ozonation and UV radiation alone). Li et al. [14] observed that phenol was oxidized rapidly by a $\mathrm{Ti} / \mathrm{SnO}_{2}-\mathrm{Sb}$ anode, and its concentration decreased from around $490 \mathrm{mg} / \mathrm{L}$ to 0 after the electrolysis for $5 \mathrm{hr}$. Ügurlu and Karaoğlu [15] reported that more than $90 \%$ phenol was degraded within $24 \mathrm{hr}$ using $\mathrm{UV} / \mathrm{H}_{2} \mathrm{O}_{2}$ and $\mathrm{UV} / \mathrm{H}_{2} \mathrm{O}_{2} / \mathrm{TiO}_{2} /$ Sepiolite, much greater than by simply using $\mathrm{UV}$ or $\mathrm{H}_{2} \mathrm{O}_{2}$ alone.

Despite the progress in AOPs research, it seems that practical applications of these AOPs have some limitations such as consumption of large amounts of chemicals (e.g., ozone and $\mathrm{H}_{2} \mathrm{O}_{2}$ ) and energy (UV and electrochemical oxidation) [16]. In this regard, we attempted to employ a novel catalyst, charge transfer auto oxidation-reduction type semiconductor catalyst (CT catalyst), for the degradation of phenol and phenolic substances. This nanosized (around $70 \mathrm{~nm}$ ) material/crystal was developed by one of the authors, Dr. Shoji Ichimura, via sintering of a mixture of $\mathrm{MnO}, \mathrm{CoO}$, and $\mathrm{TiO}_{2}$ in $\mathrm{Pt}$ and $\mathrm{Pd}$ complex powder at $1350^{\circ} \mathrm{C}$ [17]. CT is a crystal with an 8-phased perovskite form inside a 6-phased spinel structure. The core of the crystal has the base composition form with arranged electron donor and acceptor pair and electron carrier chain and oxidation/reduction center, which allows electron chain reactions to take place and be mediated. It simply relies on thermal energy to vibrate the crystal and cause electron transfer [17], which is different from photocatalysts, function with the presence of UV radiation [18]. With enough thermal energy, electron donor in CT produces electron $\left(\mathrm{e}^{-}\right)$and positive hole $\left(\mathrm{h}^{+}\right) . \mathrm{h}^{+}$moves to oxidation centre in CT to oxidize the pollutant in solution motivated by oxidation activator. The electron moves to the electron acceptor in CT by electron carrier and then reaches the reduction centre in CT to reduce substances like oxygen in water motivated by reduction activator. This catalyst has been widely used in tiles in Japan ( $>8000$ buildings as an environmentally friendly material for odor removal), but not in any other applications such as water/wastewater treatment. Yet, according to CT's remarkable characteristic that it can function in the dark, CT should have enormous potential in pollutant removal/degradation, especially in circumstances when light is not easily accessible in pollutant-carrying media (e.g., particles, cloudy water, and colored water). However, such chemical- and energy-saving applications have not been attempted previously.

In this study, we conducted experiments to degrade phenol and catechol in water using CT catalytic nanoparticles. A mild UV radiation ( $15 \mathrm{w}$, the emitted wavelength is $254 \mathrm{~nm}$ and the light intensity $<26 \mu \mathrm{w} / \mathrm{cm}^{2}$ ), not sufficient to induce effective photocatalysis in pure $\mathrm{TiO}_{2}$ catalyst [1], was provided. The hypothesis was that, following exposure to UV radiation, aromatic compounds would absorb the UV energy and reach excited state [19], upon which the CT catalysts could react (causing electron transfers). This eventually might lead to decomposition of these compounds. Compared with $\mathrm{TiO}_{2}$, we expected that CT might need low energy (mild UV radiation). Compared with $\mathrm{H}_{2} \mathrm{O}_{2}$, CT catalyst might be more efficient, because hydroxyl radicals released by $\mathrm{H}_{2} \mathrm{O}_{2}$ should be depleted with a short period of time, not be sufficient to support the mineralization of these phenolic compounds.

Overall, the objectives of this study were as follows: (1) to identify whether CT catalyst can be applied in treating/removing phenolic compound in water; (2) to determine kinetics of the catalysis process; and (3) to understand catalytic mechanisms of the CT catalysts. We hope that the data would provide fundamental information for a future design of reactors in phenolic wastewater treatment using CT catalyst.

\section{Materials and Methods}

The CT catalyst is invented by one of the authors, Dr. Shoji Ichimura, and is commercially available. CT in this study was provided by FIRAC International Co., Ltd. (Dr. Shoji Ichimura owned company) for free. Phenol, catechol, hydrogen peroxide $(30 \% \mathrm{w} / \mathrm{w})$, and $\mathrm{TiO}_{2}$ (mixture of rutile and anatase, nanopowder, $<100 \mathrm{~nm}$ ) were of analytic grade (Sigma-Aldrich Chemical Co.). Phenol and catechol were chosen as the target pollutants, and the initial concentrations were chosen at $88 \mathrm{mg} \mathrm{L}^{-1}$ (chemical oxygen demand (COD): $179 \mathrm{mg} \mathrm{L}^{-1}$; total organic carbon (TOC): $54 \mathrm{mg} \mathrm{L}^{-1}$ ) and $91.8 \mathrm{mg} \mathrm{L}^{-1}$ (COD: $164 \mathrm{mg} \mathrm{L}^{-1}$; TOC: $57 \mathrm{mg} \mathrm{L}^{-1}$ ), respectively. The $\mathrm{pH}$ level of 3 , simulating phenol-containing industrial wastewater, was adjusted using hydrochloride acid and sodium hydroxide solutions.

Four treatments, namely, pollutant $+\mathrm{UV}$, pollutant + $\mathrm{UV}+1 \% \mathrm{CT}$, pollutant $+\mathrm{UV}+1 \% \mathrm{TiO}_{2}$, and pollutant + $\mathrm{UV}+\mathrm{H}_{2} \mathrm{O}_{2}\left(60 \mu \mathrm{L} \mathrm{H}_{2} \mathrm{O}_{2}\right.$ added into $200 \mathrm{~mL}$ phenolic solution), were applied to the solutions containing phenol and catechol. Each treatment has 2 replicates. The choice of the level of CT (1\%) was based on our preliminary tests. $\mathrm{H}_{2} \mathrm{O}_{2}$ amount, as hydroxyl radical generator and scavenger, was chosen according to previous reports [20]. Flasks $(250 \mathrm{~mL})$ with the phenolic solutions were placed in a shaker, which located between two mercury UV lamps $(15 \mathrm{w}$, the emitted wavelength is $254 \mathrm{~nm}$ and the light intensity $<26 \mu \mathrm{w} / \mathrm{cm}^{2}$ ). Positions of the flasks were rotated in order to prevent an uneven exposure of the UV radiation. The experiments were conducted at room temperature $\left(20^{\circ} \mathrm{C}\right)$ and had lasted for 10-15 days until complete elimination of TOC in the flasks occurred in any treatment.

To further investigate mechanism of CT catalyst in degrading phenolic compounds, the role of CT and UV radiation in reacting with the phenol was compared. One treatment involved that a phenol solution (initial concentration of $76 \mathrm{mg} \mathrm{L}^{-1}$ ) was exposed to UV radiation for 4 days followed by $1 \%$ CT treatment in the dark. The other treatment involved a reversed sequence of the treatments in which a solution (initial concentration of $76 \mathrm{mg} \mathrm{L}^{-1}$ ) was subjected 


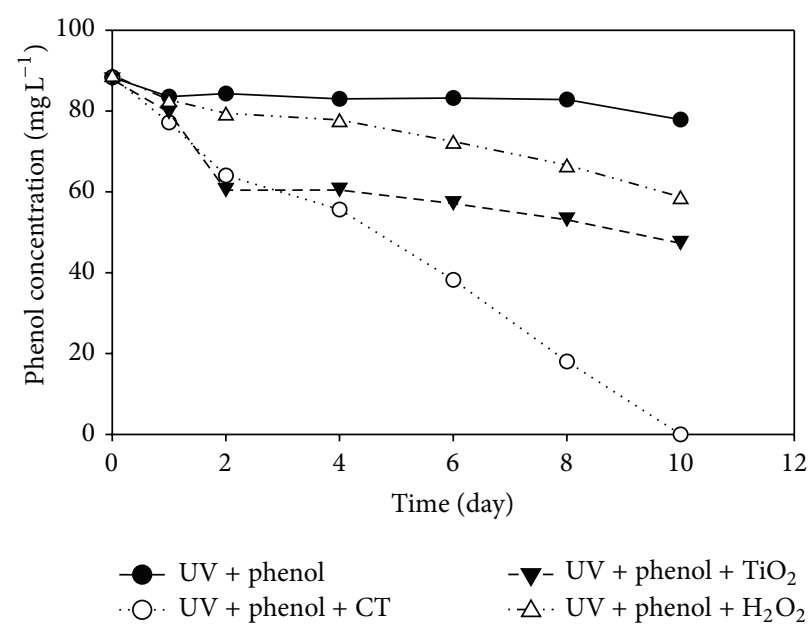

(a)

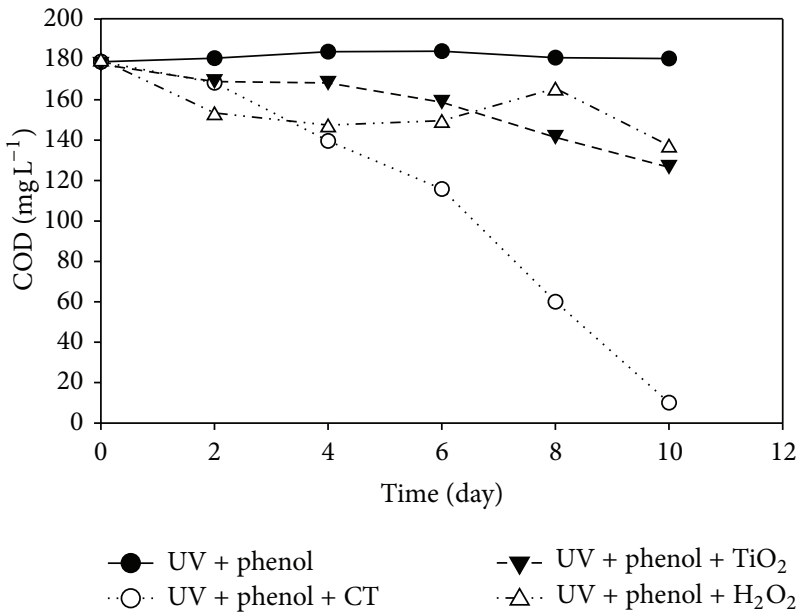

(b)

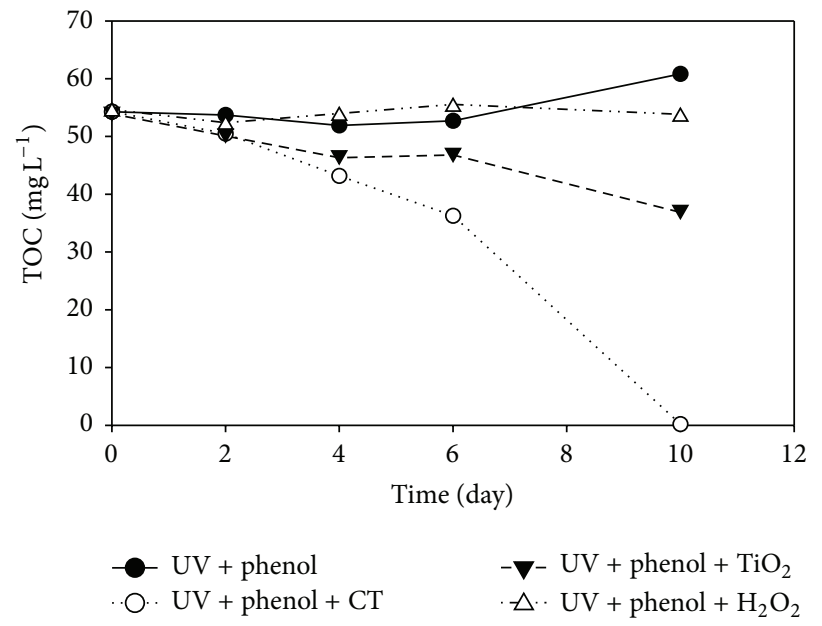

(c)

Figure 1: Time-dependent degradation of phenol by CT catalyst compared with $\mathrm{TiO}_{2}, \mathrm{H}_{2} \mathrm{O}_{2}$ ((a) phenol concentration; (b) COD; (c) TOC).

to $1 \% \mathrm{CT}$ treatment and then followed by the UV radiation. The comparison of the outcome allowed for an identification of difference between functions of UV radiation and CT catalyst.

During the experiments, the flasks were withdrawn from the shaker at predetermined time and the solutions were centrifuged at $3000 \mathrm{r} / \mathrm{min}$ for $30 \mathrm{~min}$ using a centrifuge (Allegra 6R). Concentrations of phenol, catechol, total organic carbon (TOC), chemical oxygen demand (COD), and $\mathrm{pH}$ were analyzed. Briefly, the phenol concentration was measured using the 4-aminoantipyrine method as described in Standards Methods [21], while that of catechol was measured according to Liu et al. [22]. Level of TOC was analyzed using a TOC analyzer (TOC-VCPH) based on the combustion-infrared method [23]. Level of COD was measured using open reflux method [21]. Level of $\mathrm{pH}$ was determined using a $\mathrm{pH}$ meter.

High performance liquid chromatography (HPLC, Agilent 1200), equipped with a ZORBAX column (Eclipse XDBC18 ID $=4.6 \mathrm{~mm}$, length $=150 \mathrm{~mm}$ ) and a UV detector (used at working wavelength of $215 \mathrm{~nm}$ ), was used to analyze the intermediate compounds of catechol, hydroquinone, and benzoquinone from the treatments of $\mathrm{UV}+\mathrm{CT}+$ phenol and $\mathrm{UV}+\mathrm{TiO}_{2}+$ phenol, respectively. A ratio of $1 / 3(\mathrm{~V} / \mathrm{V})$ of methanol $/ 5 \%$ orthophosphoric acid was used as the mobile phase at a flow rate of $1.0 \mathrm{~mL} \mathrm{~min}^{-1}$. The injection volume was $10 \mu \mathrm{L}$, while the column temperature was set at $25^{\circ} \mathrm{C}$. Before HPLC analysis, each sample was filtered through a $0.22 \mu \mathrm{m}$ membrane filter (water phase filter, polyethersulfone).

\section{Results and Discussion}

3.1. Removal of Phenolic Compounds by CT Catalyst. Heterogeneous photocatalytic oxidation process generally is not suitable for high concentration phenolic wastewater. Instead, it is used as the pretreatment or the posttreatment combined with the biological treatment to achieve acceptable concentration efficiently and economically feasible $[16,24]$ (Table 1).

Time-dependent degradation of phenol and catechol was shown in Figures 1 and 2, respectively. Phenol was completely removed in the treatment of phenol $+\mathrm{UV}+1 \% \mathrm{CT}$ 


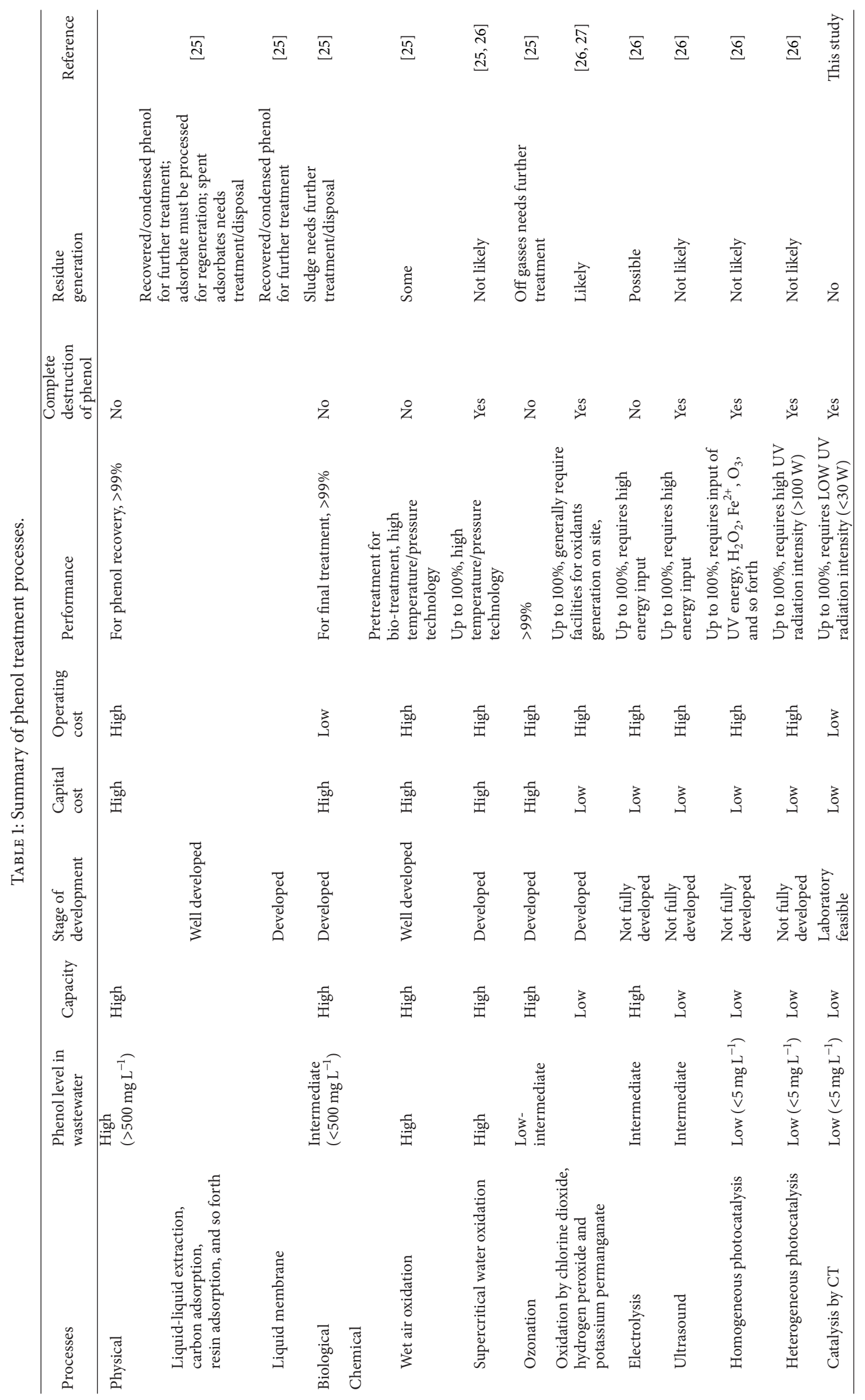




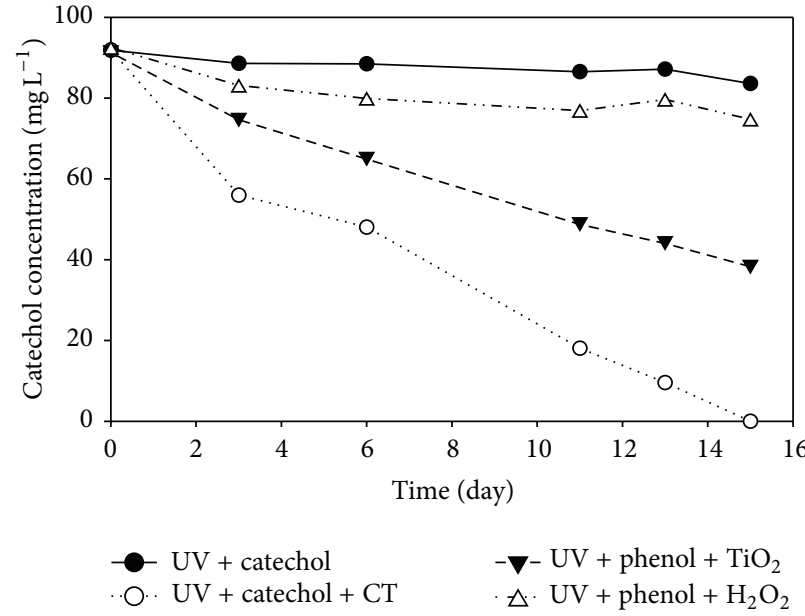

(a)

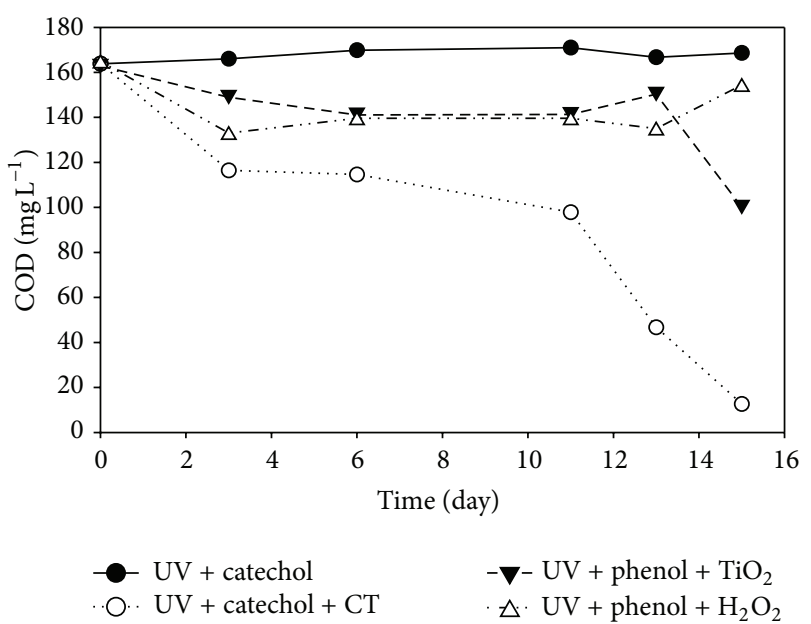

(b)

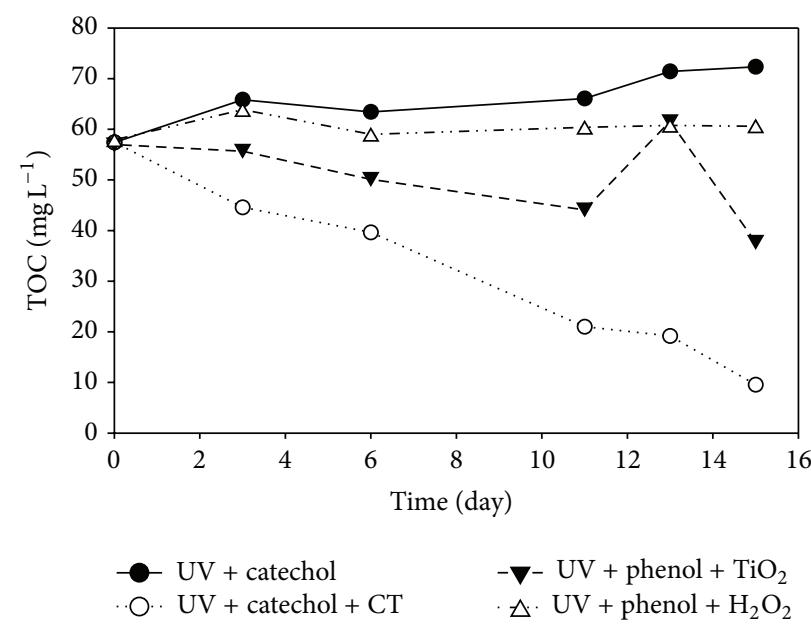

(c)

FIGURE 2: Time-dependent degradation of catechol by CT catalyst compared with $\mathrm{TiO}_{2}, \mathrm{H}_{2} \mathrm{O}_{2}$ ((a) catechol concentration; (b) COD; (c) TOC).

after 10 days (Figure 1(a)), with residues of COD $\left(10.0 \mathrm{mg} \mathrm{L}^{-1}\right)$ and TOC $\left(0.206 \mathrm{mg} \mathrm{L}^{-1}\right)$ (Figures $1(\mathrm{~b})$ and $\left.1(\mathrm{c})\right)$. In contrast, the control (phenol $+\mathrm{UV}$ ) only had a slight degradation ( $<12 \%$ phenol reduction), while $\mathrm{TiO}_{2}$ and $\mathrm{H}_{2} \mathrm{O}_{2}$ showed similar phenol removal efficiencies (34-41\% phenol reduction) (Figure 1). Pattern of the removal of catechol was similar to that of phenol (Figure 2), but a longer reaction time was required for a complete removal by CT ( $15 \mathrm{~d})$. Additionally, $\mathrm{TiO}_{2}$ was more potent than $\mathrm{H}_{2} \mathrm{O}_{2}$ in treating catechol (Figure 2(a)) that up to $57.8 \%$ of the catechol removal occurred in the treatment by $\mathrm{TiO}_{2}$, much higher than the treatment by $\mathrm{H}_{2} \mathrm{O}_{2}(19.3 \%)$ and the control (8.9\%).

The processes of phenol/catechol removal followed pseudo-zero-order kinetics (Figure 3), whereas correlation coefficients for the pseudo-first-order kinetic model were generally low. This suggested that mass transfer was not a rate controlling process in the experiments [23]. However, the result was different from previous studies that phenol removal mostly followed pseudo-first-order kinetics [16, 2830]. Further investigation is needed in order to understand more of the mechanisms. UV+TiO for phenol and catechol and $\mathrm{UV}+\mathrm{H}_{2} \mathrm{O}_{2}$ for phenol and catechol follow pseudofirst-order kinetics, and the calculated rate constant $k$ values were $0.03 \times 10^{-3} / \mathrm{min}, 0.04 \times 10^{-3} / \mathrm{min}, 0.03 \times 10^{-3} / \mathrm{min}$, and $0.01 \times 10^{-3} / \mathrm{min}$, respectively. But UV + CT follows pseudo-zero-order kinetic calculated rate constant $k$ values (for phenol and catechol) were $5.28 \times 10^{-3} \mathrm{~mol} \mathrm{~L}^{-1} \mathrm{~min}^{-1}$ and $4.59 \times 10^{-3} \mathrm{~mol} \mathrm{~L}^{-1} \mathrm{~min}^{-1}$, according to slopes of the regression models (Figure 3 ) (slope $=k$ /initial concentration of phenol/catechol).

The result demonstrated that CT catalyst could be used for a complete removal of phenolic compounds in wastewater, with the presence of mild UV radiation $(15 \mathrm{w}$, the emitted wavelength is $254 \mathrm{~nm}$ and the light intensity $<26 \mu \mathrm{w} / \mathrm{cm}^{2}$ ). Compared with previous reports on phenol degradation, such as employing sono-/photo-Fenton reactions [11], immobilized $\mathrm{TiO}_{2}$ photodegradation [31], or electrochemical oxidation [28], the present treatment using CT catalyst had notably advantage of (1) less energy consumption and (2) no chemical consumption. Further comparison of the UV 


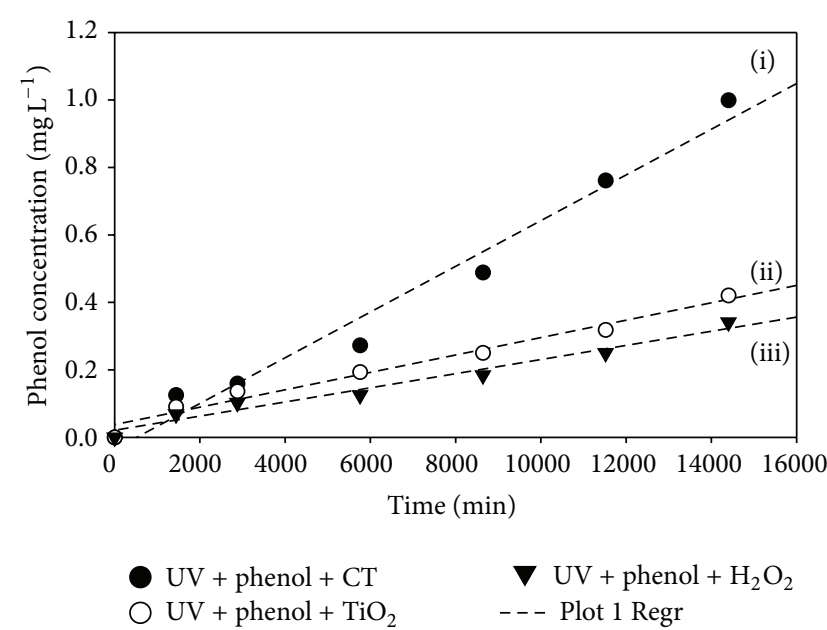

(a)

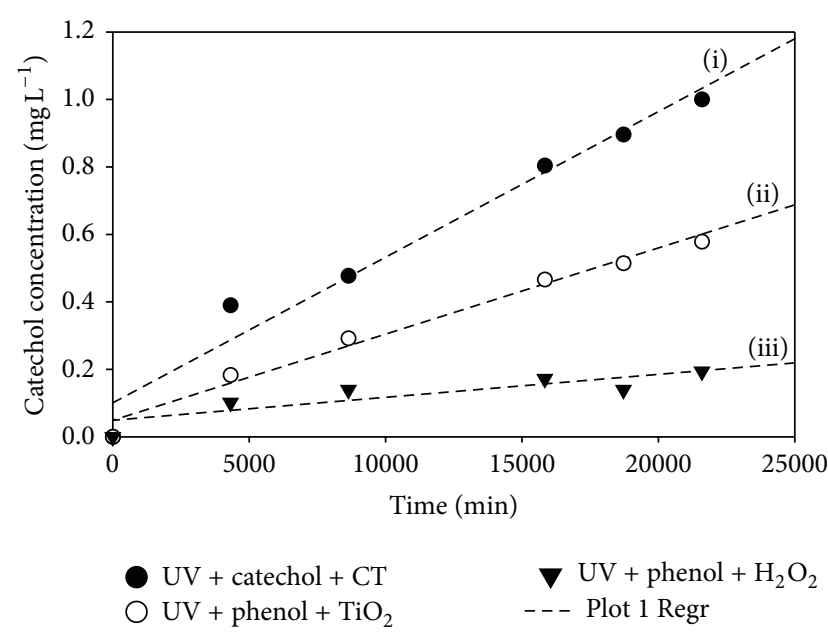

(b)

FIGURE 3: Degradation kinetics of (a) phenol: (i) $y=7 * 10^{-5} x-0.0288, r^{2}=0.9761$; (ii) $y=3 * 10^{-5} x+0.0349, r^{2}=0.9767$; (iii) $y=2 * 10^{-5} x+0.0628, r^{2}=0.9902$; and (b) catechol: (i) $y=4 * 10^{-5} x+0.0951, r^{2}=0.9686$; (ii) $y=3 * 10^{-5} x+0.0426, r^{2}=0.9831$; (iii) $y=7 * 10^{-6} x+0.0432, r^{2}=0.7685$.

TABLE 2: Comparison of UV intensity adopted by varied studies in photodegradation of phenol.

\begin{tabular}{|c|c|c|c|}
\hline Treatment & Reaction condition & Performance & Study \\
\hline $\begin{array}{l}\mathrm{UV}+\mathrm{H}_{2} \mathrm{O}_{2}+\mathrm{TiO}_{2} \text { supported on } \\
\text { sepiolite }\end{array}$ & $\begin{array}{l}\text { UV intensity } 17 \mathrm{w} \text {; } \mathrm{pH} \text { 5.5; solid/liquid } \\
0.5 \mathrm{~g} \mathrm{~L}^{-1} ; \mathrm{H}_{2} \mathrm{O}_{2}: 30 \mathrm{ml} \mathrm{L}^{-1}\end{array}$ & $\begin{array}{l}k=0.87 \times 10^{-3} / \mathrm{min}, \text { within } \\
24-25 \mathrm{~h}, \text { conversion }>90 \%\end{array}$ & $\begin{array}{l}\text { Ŭgurlu and } \\
\text { Karaoğlu } 2011 \\
{[15]}\end{array}$ \\
\hline $\mathrm{UV}+\mathrm{TiO}_{2} /$ perlite & $\begin{array}{l}\mathrm{UV} \text { intensity } 250 \mathrm{w} \text {, pH } 10.7 \text {; initial } \\
\text { phenol concentration } 0.5 \mathrm{mmol} \mathrm{L}^{-1} \text {; } \\
\mathrm{TiO}_{2} \text { /perlite dosage, } 6 \mathrm{~g} \mathrm{~L}^{-1} \text {; reaction } \\
\text { temperature } 27^{\circ} \mathrm{C}\end{array}$ & Experimental conversion (\%): 97.3 & $\begin{array}{l}\text { Jafarzadeh et al. } \\
2011[1]\end{array}$ \\
\hline Sono-photo-Fenton & $\begin{array}{l}\text { UV intensity } 250 \mathrm{w} \text {, emitting radiation } \\
\text { between } 300-420 \mathrm{~nm} ; \mathrm{pH} 3 ; \mathrm{Fe}^{2+} \\
20 \mathrm{mg} \mathrm{L}^{-1}, \mathrm{H}_{2} \mathrm{O}_{2} 700 \mathrm{mg} \mathrm{L}^{-1} \text {, room } \\
\text { temperature }\end{array}$ & $\begin{array}{l}93 \% \text { phenol reduction, } 84.6 \% \text { COD } \\
\text { reduction within } 60 \mathrm{~min} \text {, } \\
k=0.1186 / \mathrm{min}\end{array}$ & $\begin{array}{l}\text { Babuponnusami } \\
\text { and } \\
\text { Muthukumar } \\
2011[11]\end{array}$ \\
\hline $\mathrm{UV} / \mathrm{H}_{2} \mathrm{O}_{2}$ & $\begin{array}{l}\text { UV intensity } 5000 \text { w output; } \mathrm{H}_{2} \mathrm{O}_{2} \\
\text { concentration: } 7.08 \mathrm{mmol} \mathrm{L}^{-1}\end{array}$ & $\begin{array}{l}\text { Within } 50 \mathrm{~min}, 50 \mathrm{mg} \mathrm{L}^{-1} \text { phenol } \\
\text { degraded into } 10 \mathrm{mg} \mathrm{L}^{-1}\end{array}$ & $\begin{array}{l}\text { Huang and Shu } \\
\text { [33] }\end{array}$ \\
\hline $\begin{array}{l}\mathrm{UV} / \mathrm{TiO}_{2} \text { supported } \\
\text { on fiberglass cloth }\end{array}$ & $\begin{array}{l}\text { a UV/Vis mercury lamp: } 6 \mathrm{Kw}, 330 \mathrm{Wm}^{-2} \\
\text { initial phenol Concentration: } 25 \mathrm{mg} \mathrm{L}^{-1}\end{array}$ & $80 \%$ phenol reduction within $15 \mathrm{~h}$ & $\begin{array}{l}\text { Mozia et al. } 2012 \\
\text { [32] }\end{array}$ \\
\hline $\mathrm{UV} / \mathrm{CT}$ & $\begin{array}{l}\text { UV intensity } 15 \mathrm{w} \text {, the emitted wavelength } \\
\text { is } 254 \mathrm{~nm} \text { and the light intensity } \\
<26 \mu \mathrm{w} / \mathrm{cm}^{2} ; \mathrm{pH} 3 \text {, initial phenol } \\
\text { concentration } 88 \mathrm{mg} \mathrm{L}^{-1} \\
\left(0.936 \mathrm{mmol} \mathrm{L}^{-1}\right), 1 \% \mathrm{CT} \text { nanoparticles; } \\
\text { room temperature }\end{array}$ & $\begin{array}{l}\text { Within } 10 \text { day, } 100 \% \text { degradation, } \\
k=5.28 \times 10^{-3} \mathrm{~mol} \mathrm{~L}^{-1} \mathrm{~min}^{-1}\end{array}$ & This study \\
\hline
\end{tabular}

intensity among varied photodegradation of phenol (Table 2) demonstrated that CT catalyst required low UV radiation ( $15 \mathrm{w}$, the emitted wavelength is $254 \mathrm{~nm}$ and the light intensity $<26 \mu \mathrm{w} / \mathrm{cm}^{2}$ ). This suggested that the present set-up using CT catalysis could be applied in removing wastewater containing low levels of phenol. Although it took CT 10 and 15 days to mineralize phenol and catechol (both with the initial concentration of $88 \mathrm{mg} \mathrm{L}^{-1}$ ), respectively, CT/UV followed zeroorder kinetics, suggesting the reaction rate constant was not a function of phenol concentration. If CT/UV is applied for posttreatment, with much lower concentrations $\left(<5 \mathrm{mg} \mathrm{L}^{-1}\right)$ of phenol or catechol, less removal time is expected. Nevertheless, our follow-up experiments verified our hypothesis (unpublished). The band gap energy of $\mathrm{TiO}_{2}$ is up to $3.2 \mathrm{eV}$. Usually $\mathrm{TiO}_{2}$ absorbs light with the wavelength less than $385 \mathrm{~nm}$. Previous reports by other researchers showed that the UV intensity is a critical parameter in order to allow $\mathrm{TiO}_{2}$ to function efficiently $[16,32]$. Compared with $\mathrm{TiO}_{2} / \mathrm{UV}$, 


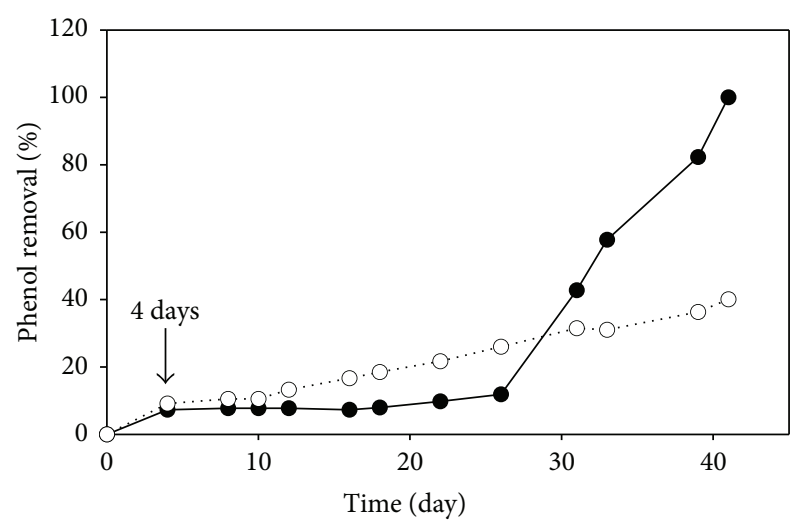

(A)

(B)

FIgURE 4: Sequential degradation of phenol: (A) four days of UV radiation followed by $1 \% \mathrm{CT}$ treatment in the dark; (B) four days of $1 \% \mathrm{CT}$ in the dark followed by UV radiation.

CT has the advantage that it works better under mild UV intensity. Further investigation will be needed for treating water with higher phenol level; the pollutants treatment efficiency also needs to be improved and optimized.

The result of the treatments of $\mathrm{UV}+\mathrm{H}_{2} \mathrm{O}_{2}$ and $\mathrm{UV}+\mathrm{TiO}_{2}$ was expected. For the former treatment, the one-time spiking of $\mathrm{H}_{2} \mathrm{O}_{2}$ limited a continuous supply of hydroxyl radicals, leading to an incomplete mineralization of the phenolic compounds. For example, we observed that the solution in the treatment of phenol $+\mathrm{UV}+\mathrm{H}_{2} \mathrm{O}_{2}$ turned from colorless at the start of the experiment to dark brown at the end (10 days). For the latter, due to the low UV intensity provided, $\mathrm{TiO}_{2}$ did not absorb enough photon energy to form sufficient holes $\left(\mathrm{h}^{+}\right)$and hydroxyl radicals [34], which are the most important species for oxidation organic compounds [31]. As a result, low levels of phenolic compounds were decomposed.

\subsection{Mechanism of CT Catalyst in Degrading Phenolic Com-} pounds. Although complete removal of phenol was achieved with the copresence of CT and UV (Figure 1), sequential degradations of phenol (treatment by UV followed by CT (A) and treatment by CT followed by UV (B)) showed much lower efficiency (Figure 4). For example, both treatments (A and $\mathrm{B}$ ) at 4 days showed $<10 \%$ phenol removal (Figure 4 ), whereas the treatment with the copresence of CT and UV at 4 days removed $26.8 \%$ phenol (Figure $1(\mathrm{a})$ ). It took 40 days for a complete removal of phenol in treatment A (Figure 4), but 10 days in the copresence of CT and UV (Figure 1(a)). This indicated that the copresence of CT and UV had a synergistic effect in degrading phenol.

Moreover, remarkable difference was observed between treatments $\mathrm{A}$ and $\mathrm{B}$ (Figure 4). At 26 days, treatment $\mathrm{A}$ started to show a remarkable increasing removal percentage (>6\%/day), and eventually at 40 days phenol was completely removed $(100 \%)$. In contrast, the increase in the removal percentage of treatment B was not significant $(<40 \%)$ during the whole treatment period (40 days). This proved that CT and UV did not play an equal role in phenol degradation. For treatment $B$, the slight decrease in phenol in the treatment $\mathrm{B}$ (by CT and then UV) most likely was due to residue CT catalyst in the filtrate after filtration. However, for treatment $\mathrm{A}$, it is more probable that the phenolic compounds absorbed the UV energy and passed to the higher state of energy (excited state) first, and then in the dark the unstable excited-state phenolic compounds underwent charge transfer processes mediated by the CT catalyst. In particular, under acidic condition, electron donor of CT generated holes, which moved towards the oxidation center, and pulled electrons out from the phenolic compounds, and therefore the phenolic compounds were oxidized. The reduction center of the CT accepted those electrons and sent them to electron acceptors, such as oxygen in the water. In this regard, whether the pseudo-zero-order kinetic model derived from the present kinetic study reflected a rate limiting influence by the charge transfer process remained to be investigated. Another explanation can be that hydroxyl radicals were generated from CT in the solution [35] that the phenolic compounds adsorbed on the surface of CT were oxidized and mineralized. However, concentration of the hydroxyl radicals was not measured in the present study, but should be examined in the future. The contrast of the result of treatments A and B partially supported our hypothesis on the functions of UV and CT and the associated mechanism, which indicates that CT has the potential for degrading organics in the dark condition, although uncertainties remained to be clarified in our future work.

Probable pathway of phenol degradation in water was established according to previous studies, that is, phenol-catechol or hydroquinone/benzoquinone-maleic acid-acrylic acid/succinic-malonic acid-acetic acid- $\mathrm{CO}_{2}+$ $\mathrm{H}_{2} \mathrm{O}[14,36-38]$, and the identified and quantified intermediates in the present phenol degradations (UV + CT and $\mathrm{UV}+\mathrm{TiO}_{2}$ ) were shown in Figure 5. Furthermore, levels of TOC calculated based on the carbon concentrations in the intermediates (Figure 5) were also compared with the corresponding measured TOC concentrations using a TOC analyzer (Figures 1(c) and 2(c)) (Table 3). For the treatment of UV + CT, it seems that the three measured compounds (catechol, hydroquinone, and benzoquinone) were the predominant intermediates, accounting for more than $95 \%$ of the measured TOC (Figure 5(a)). Concentrations of catechol and hydroquinone reached the maxima (catechol: $0.826 \mathrm{mg} \mathrm{L}^{-1}$; hydroquinone: $4.43 \mathrm{mg} \mathrm{L}^{-1}$ ) at $2 \mathrm{~d}$, while that of benzoquinone only peaked at 6 days $\left(1.02 \mathrm{mg} \mathrm{L}^{-1}\right)$. At 10 days, a complete mineralization occurred, in which all intermediates were transformed into the end products $\left(\mathrm{CO}_{2}\right.$ and $\mathrm{H}_{2} \mathrm{O}$ ). However, varied acids as intermediates between benzoquinone and the end products were not detectable. Based on mass balance, these compounds accounted for $<5 \%$ of the TOC (Table 3 ). Similarly, acids were not detected in the treatment of $\mathrm{UV}+\mathrm{TiO}_{2}$, accounting for $<10 \%$ of the TOC (Table 3), whereas only catechol and hydroquinone were identified and quantifiable (Figure 5(b)). The difference between these two treatments was expected as the UV intensity was low and $\mathrm{TiO}_{2}$ could not generate adequate energy and radicals for the degradation. 


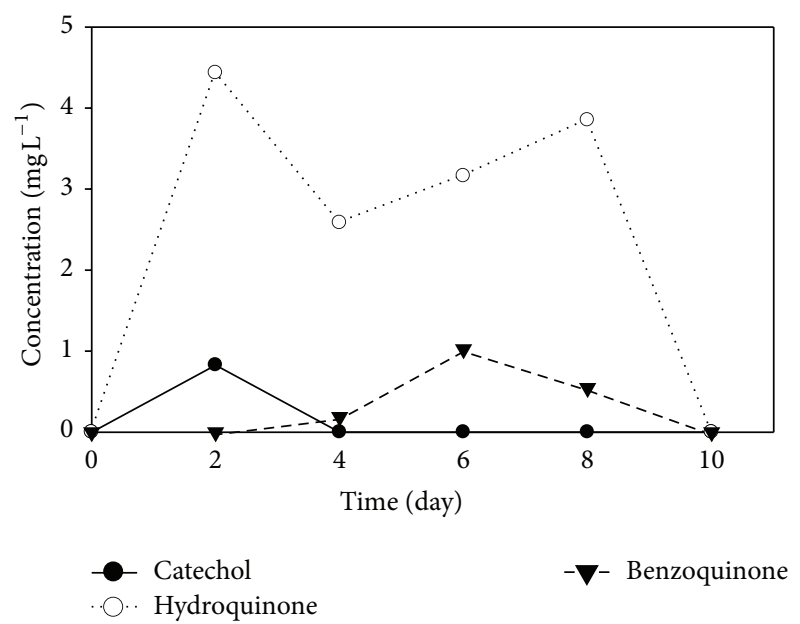

(a)

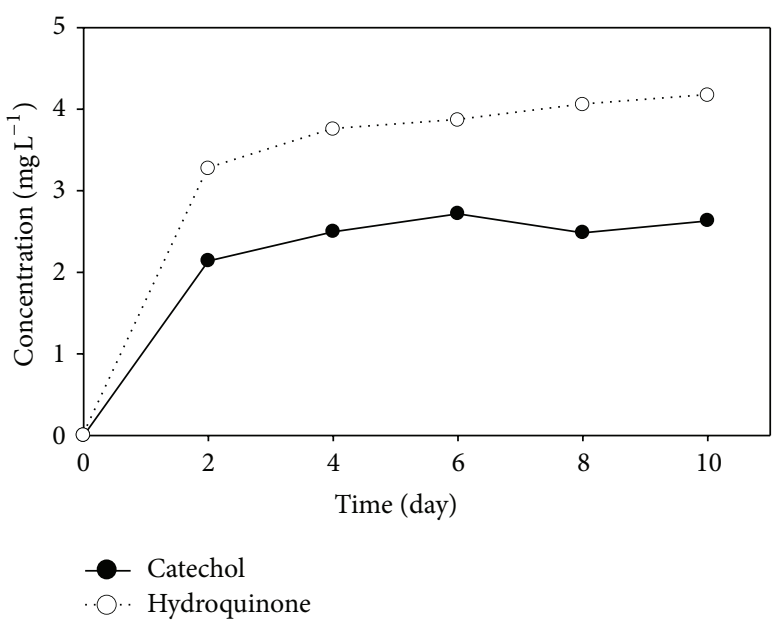

(b)

FIGURE 5: Degradation intermediates of phenol from the treatment of (a) $\mathrm{UV}+\mathrm{CT}$ and (b) $\mathrm{UV}+\mathrm{TiO}_{2}$.

TABLE 3: Levels of TOC calculated from carbon contents in phenol and its intermediates compared with TOC concentrations measured by a TOC analyzer.

\begin{tabular}{|c|c|c|c|c|c|}
\hline \multirow{2}{*}{ TOC $\left(\mathrm{mg} \mathrm{L}^{-1}\right)$} & \multicolumn{5}{|c|}{ Time (day) } \\
\hline & 0 & 2 & 4 & 6 & 10 \\
\hline \multicolumn{6}{|l|}{$\mathrm{UV}+\mathrm{CT}$} \\
\hline Phenol & 67.4 & 49.0 & 42.6 & 29.3 & ND \\
\hline Catechol & ND & 0.541 & ND & $\mathrm{ND}$ & ND \\
\hline Hydroquinone & ND & 2.90 & 1.69 & 2.07 & ND \\
\hline Benzoquinone & ND & ND & 0.125 & 0.683 & ND \\
\hline Total calculated value & 67.4 & 52.4 & 44.4 & 32.0 & ND \\
\hline Measured value & 54.3 & 50.5 & 43.2 & 36.3 & 0.206 \\
\hline \multicolumn{6}{|l|}{$\mathrm{UV}+\mathrm{TiO}_{2}$} \\
\hline Phenol & 67.4 & 46.7 & 46.7 & 44.2 & 36.7 \\
\hline Catechol & ND & 1.40 & 1.63 & 1.78 & 1.72 \\
\hline Hydroquinone & ND & 2.14 & 2.45 & 2.53 & 2.73 \\
\hline Total calculated value & 67.4 & 50.3 & 50.8 & 48.5 & 41.1 \\
\hline Measured value & 54.3 & 50.5 & 46.7 & 47.1 & 37.3 \\
\hline
\end{tabular}

\section{Conclusions}

This is the first report on employing CT catalyst, a novel charge transfer auto oxidation-reduction type of semiconductor, in degrading aromatic compounds in water. Phenolic compounds (initial concentrations, phenol: $88 \mathrm{mg} \mathrm{L}^{-1}$ and catechol: $91.8 \mathrm{mg} \mathrm{L}^{-1}$ ) were completely mineralized by the CT catalytic nanoparticles (1\%) within 15 days, under acidic condition and with the presence of mild UV radiation $(15 \mathrm{w}$, the emitted wavelength is $254 \mathrm{~nm}$ and the light intensity $\left.<26 \mu \mathrm{w} / \mathrm{cm}^{2}\right)$. The reaction condition allowed CT to be applied in pollutant removal in wastewater that light transfer was quite often a challenge if photocatalysis was attempted. Phenol elimination followed pseudo-zero-order kinetics with a rate constant of $5.28 \times 10^{-3} \mathrm{~mol} \mathrm{~L}^{-1} \mathrm{~min}^{-1}$ under the present treatment condition. It seems that, given low initial phenol concentration, a circumstance encountered in wastewater polishing, the current set-up should be more efficient and less energy-/chemical-consumptive.

A probable mechanism of the CT's functions related to a synergistic performing between UV radiation and the CT. In particular, the aromatic structures in phenol absorbed the UV energy and passed to an excited state. The CT worked on these excited compounds by absorbing pollutants on the surface, oxidizing the pollutants via charge transfer, and producing hydroxyl radicals and eventually completely transformed all the pollutants to $\mathrm{CO}_{2}$ and $\mathrm{H}_{2} \mathrm{O}$. Analysis of the degradation intermediates of phenol showed that the reaction in the CT's treatment followed general pathway observed by other researchers. In the practical application, CT can be separated from the effluent through nanofiltration. 


\section{Conflict of Interests}

The authors declare that there is no conflict of interests regarding the publication of this paper.

\section{Acknowledgments}

This study was supported by "100 Talents Program" of Chinese Academy of Sciences and the Faculty Research Grant (FRG2/09-10/027, Faculty of Science of Hong Kong Baptist University) awarded to Yan Liang.

\section{References}

[1] N. K. Jafarzadeh, S. Sharifnia, S. N. Hosseini, and F. Rahimpour, "Statistical optimization of process conditions for photocatalytic degradation of phenol with immobilization of nano $\mathrm{TiO}_{2}$ on perlite granules," Korean Journal of Chemical Engineering, vol. 28, no. 2, pp. 531-538, 2011.

[2] S. P. Mahajan, Pollution Control in Processes Industries, Tata McGraw-Hill, New Delhi, India, 1994.

[3] Y. M. Dong, G. L. Wang, P. P. Jiang, A. M. Zhang, L. Yue, and X. M. Zhang, "Catalytic ozonation of phenol in aqueous solution by $\mathrm{Co}_{3} \mathrm{O}_{4}$ nanoparticles," Bulletin of the Korean Chemical Society, vol. 31, no. 10, pp. 2830-2834, 2010.

[4] U.S. Environmental Protection Agency, "Toxicological review of phenol," Support of Summary Information on the Integrated Risk Information System EPA /635/r-02/006, Environmental Protection Agency, Washington, DC, USA, 2002.

[5] Ministry of Environmental Protection of the P. R. China (SEPA), Integrated Wastewater Discharge Standard (GB 8978-1996), Environmental Protection National Standard of the People's Republic of China, 1996.

[6] M. Ahmaruzzaman and D. K. Sharma, "Adsorption of phenols from wastewater," Journal of Colloid and Interface Science, vol. 287, no. 1, pp. 14-24, 2005.

[7] M. J. Gonzalez-Munoz, S. Luque, J. R. Alvarez, and J. Coca, "Recovery of phenol from aqueous solutions using hollow fibre contactors," Journal of Membrane Science, vol. 213, no. 1-2, pp. 181-193, 2003.

[8] J.-Q. Xu, W.-H. Duan, X.-Z. Zhou, and J.-Z. Zhou, "Extraction of phenol in wastewater with annular centrifugal contactors," Journal of Hazardous Materials, vol. 131, no. 1-3, pp. 98-102, 2006.

[9] S. Li, R. Kong, L. Sun, S. F. Li, and S. C. Yang, "study on treatment methods of phenol in industrial wastewater," International Journal of Scientific \& Engineering Research, vol. 4, no. 5, pp. 230-232, 2013.

[10] X. Han, The Study of Photocatalytic Oxidation of the Wastewater with High Concentration of Phenol and Formaldehyde, Si Chuan University, Chengdu, China, 2004.

[11] A. Babuponnusami and K. Muthukumar, "Degradation of phenol in aqueous solution by fenton, sono-fenton and sonophoto-fenton methods," Clean-Soil, Air, Water, vol. 39, no. 2, pp. 142-147, 2011.

[12] P. J. Ranjit, K. Palanivelu, and C. S. Lee, "Degradation of 2,4dichlorophenol in aqueous solution by sono-fenton method," Korean Journal of Chemical Engineering, vol. 25, no. 1, pp. 112117, 2008.
[13] M. D. Gurol and R. Vatistas, "Oxidation of phenolic compounds by ozone and ozone+UV radiation: a comparative study," Water Research, vol. 21, no. 8, pp. 895-900, 1987.

[14] X.-Y. Li, Y.-H. Cui, Y.-J. Feng, Z.-M. Xie, and J.-D. Gu, "Reaction pathways and mechanisms of the electrochemical degradation of phenol on different electrodes," Water Research, vol. 39, no. 10, pp. 1972-1981, 2005.

[15] M. Ügurlu and M. H. Karaoğlu, " $\mathrm{TiO}_{2}$ supported on sepiolite: preparation, structural and thermal characterization and catalytic behaviour in photocatalytic treatment of phenol and lignin from olive mill wastewater," Chemical Engineering Journal, vol. 166, no. 3, pp. 859-867, 2011.

[16] J. C. Costa and M. Madalena, "posttreatment of Olive mill wastewater by immobilized $\mathrm{TiO}_{2}$ photocatalysis," Photochemistry and Photobiology, vol. 89, pp. 545-551, 2013.

[17] S. Ichimura and K. Ichimura, "Charge transfer auto-oxidationreduction semiconductor catalyst: application to MINOYAKI tiles and it's effects," Transactions of the Materials Research Society of Japan, vol. 26, no. 3, pp. 1045-1048, 2001.

[18] M. R. Hoffmann, S. T. Martin, W. Choi, and D. W. Bahnemann, "Environmental applications of semiconductor photocatalysis," Chemical Reviews, vol. 95, no. 1, pp. 69-96, 1995.

[19] F. J. Beltrbn, G. Ovejero, J. F. Garcla-Araya, and J. Rivas, "Oxidation of polynuclear aromatic hydrocarbons in water. 2. UV radiation and ozonation in the presence of UV radiation," Industrial and Engineering Chemistry Research, vol. 34, no. 5, pp. 1607-1615, 1995.

[20] M. L. Zhou, L. Li, and Y. Li, "Study on effect of catalytic oxidation of phenol by $\mathrm{H}_{2} \mathrm{O}_{2}$," Environmental Science Survey, vol. 28, no. 2, pp. 8-10, 2009.

[21] American Public Health Association, Standard Methods for the Examination of Water and Waste Water, American Public Health Association, Washington DC, USA, 20th edition, 1998.

[22] W. Liu, J. D. Liu, Z. L. Wang et al., "Determination of catechol content of the willow by Colorimetry," Chinese Traditional and Herbal Drugs, vol. 33, p. 134, 2002.

[23] P. S. Kumar, K. Ramakrishnan, S. D. Kirupha, and S. Sivanesan, "Thermodynamic, kinetic, and equilibrium studies on phenol removal by use of cashew nut shell," Canadian Journal of Chemical Engineering, vol. 89, no. 2, pp. 284-291, 2011.

[24] H. Liu and P. Liu, "The study of heterogeneous photocatalytic oxidation of coking wastewater," Environmental Science and Technology, vol. 29, no. 2, pp. 103-105, 2006.

[25] USEPA, "Technical resources document: treatment technologies for solvent containing wastes," Hazardous Waste Engineering Research Laboratory EPA/600/2-86/O095, Cincinnati, Ohio, USA, 1986.

[26] X. Deng, D. S. Li, Y. F. Li, F. J. Liang, and C. Y. Zhang, "Advanced oxidation technologies of the removal of phenol wastewater," Water Science and Engineering Technology, vol. 1, pp. 26-30, 2008.

[27] Siemens Water Technologies, "Application Note: Phenol Destruction with Chlorine Dioxide," WT. 085. 272. 013.IE.AN. 0409, Siemens, 2009, http://www.industry.siemens.com/industrysolutions/de/en/water-treatment/Pages/Default.aspx.

[28] Y. H. Cui, Y. J. Feng, and X. Y. Li, "Kinetics and efficiency analysis of electrochemical oxidation of phenol: influence of anode materials and operational conditions," Chemical Engineering and Technology, vol. 34, no. 2, pp. 265-272, 2011.

[29] R. Kar, O. Gupta, K. Mandol, and S. Bhattacharjee, "Performence study on photocatalysis of phenol solution in a UV 
irradiated reactor," Journal of Chemical Engineering \& Process Technology, vol. 4, article 143, 2013.

[30] M. Delnavaz, B. Ayati, H. Ganjidoust, and S. Sanjabi, "kinetics study of photocatalytic process for treatment of phenolic wastewater by $\mathrm{TiO}_{2}$ nano powder immobilized on concrete surfaces," Toxicological and Environmental Chemistry, vol. 94, no. 6, pp. 1086-1098, 2012.

[31] H.-J. Wang and X.-Y. Chen, "Kinetic analysis and energy efficiency of phenol degradation in a plasma-photocatalysis system," Journal of Hazardous Materials, vol. 186, no. 2-3, pp. 1888-1892, 2011.

[32] S. Mozia, P. Brozek, J. Przepiorski, B. Tryba, and A. W. Morawski, "Immobilized $\mathrm{TiO}_{2}$ for phenol degradation in a pilot-scale photocatalytic reactor," Journal of Nanomaterials, vol. 2012, Article ID 949764, 10 pages, 2012.

[33] C. R. Huang and H. Y. Shu, "The reaction kinetics, decomposition pathways and intermediate formations of phenol in ozonation, $\mathrm{UV} / \mathrm{O}_{3}$, and $\mathrm{UV} / \mathrm{H}_{2} \mathrm{O}_{2}$ processes," Journal of Hazardous Materials, vol. 41, pp. 47-64, 1995.

[34] J.-C. Lee, M.-S. Kim, C. K. Kim et al., "Removal of paraquat in aqueous suspension of $\mathrm{TiO}_{2}$ in an immersed UV photoreactor," Korean Journal of Chemical Engineering, vol. 20, no. 5, pp. 862868, 2003.

[35] K. L. Chow, N. A. Mak, M. H. Wong, X. F. Zhou, and Y. Liang, "Generation of reactive oxygen species and oxidative stress in Escherichia coli and Staphylococcus aureus by a novel semiconductor catalyst," Journal of Nanoparticle Research, vol. 13, no. 3, pp. 1007-1017, 2011.

[36] N. Al-Hayek and M. Dore, "Oxidation of phenols in water by hydrogen peroxide on alumine supported iron," Water Research, vol. 24, no. 8, pp. 973-982, 1990.

[37] L. F. Liotta, M. Gruttadauria, G. DiCarlo, G. Perrini, and V. Librando, "Heterogeneous catalytic degradation of phenolic substrates: catalysts activity," Journal of Hazardous Materials, vol. 162, no. 2-3, pp. 588-606, 2009.

[38] A. Mokrini, D. Ousse, and S. Esplugas, "Oxidation of aromatic compounds with UV radiation/ozone/hydrogen peroxide," Water Science and Technology, vol. 35, no. 4, pp. 95-102, 1997. 

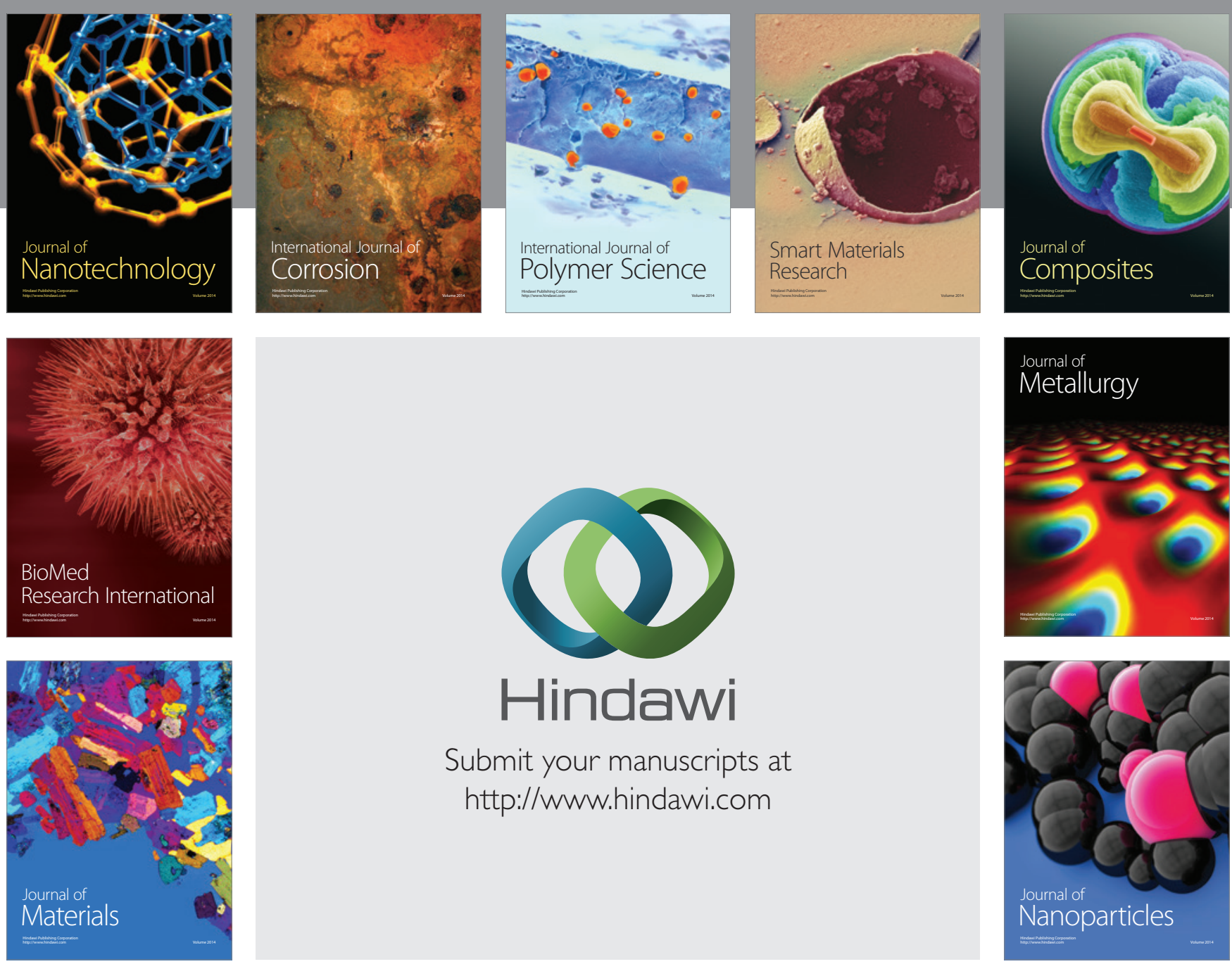

Submit your manuscripts at http://www.hindawi.com
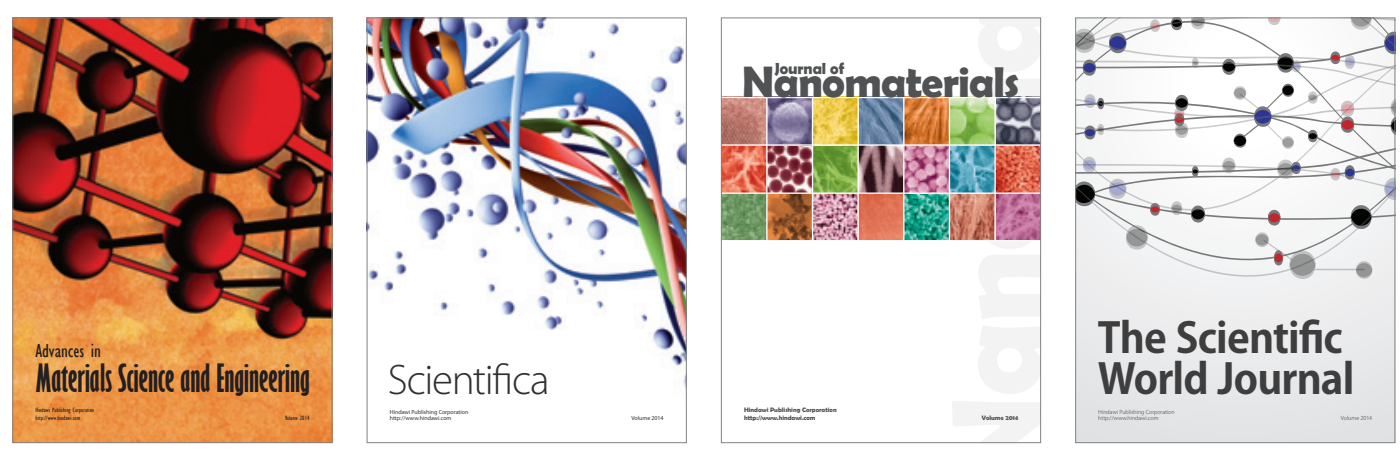

\section{The Scientific World Journal}
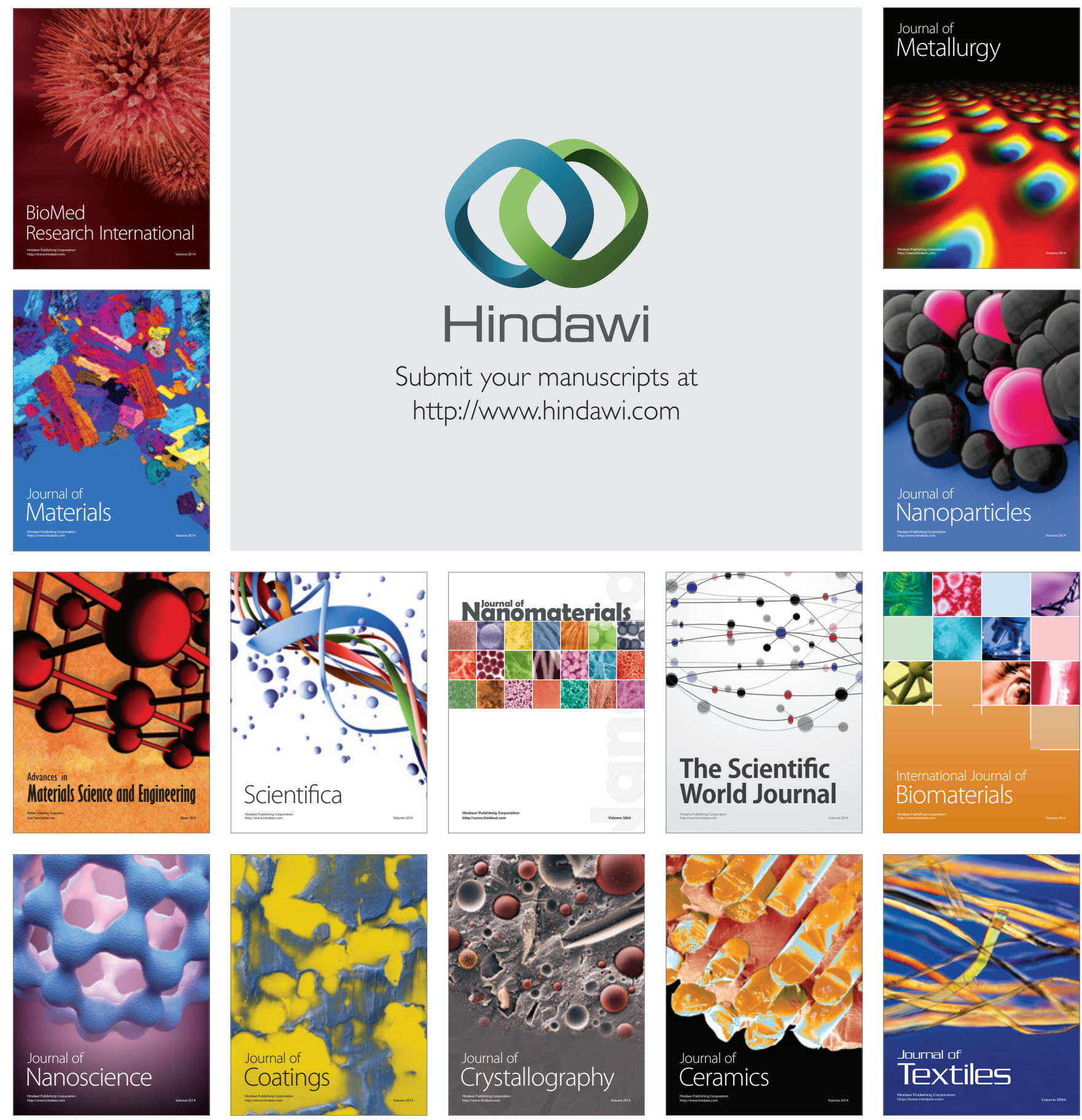